\title{
Innovative Thinking and Application of Integrating Regional Culture into the Design of Cultural and Creative Products
}

\author{
Zhi Zi \\ Department of Visual Communication Design, School of Art and Design, Fuzhou Foreign \\ Languages and Foreign Trade College Fuzhou, Fujian 350202
}

Keywords: functionality; products; design; innovation

\begin{abstract}
The creative dimension of creative product design with regional characteristics can be developed from three aspects: the acquisition of lifestyle and creativity, the expression of values and creativity, and the influence of foreign cultural factors on creativity. Cultural and creative product design itself is a visual statement of the elements related to the product by the designer. The designer grasps the visual semantics and converts it into modelling language, so that the audience can get sufficient information, cognitive and emotional recognition, achieve the purchase intention, and complete the dissemination of cultural creativity. Efforts should be made to enrich people's spiritual life, stimulate people's interest in life, create an environment and use scenarios, and meet the psychological and spiritual needs of the audience.
\end{abstract}

Material decides consciousness and economic foundation decides superstructure. In the design work of cultural creative products, experiencing regional life, excavating regional cultural symbols and diverging creative thinking to develop cultural creative products with regional characteristics have become an important proposition for the design of cultural creative products. Cultural and creative products have practical, cognitive and aesthetic functions of general commodities. Especially the aesthetic function, through the product to the audience intuitively and enjoy the use of experience. In order to achieve aesthetic function of literary products, we must make the designs contain cultural and spiritual connotations beyond the senses, so as to arouse the life interest and value experience of the product audience.

In order to realize the aesthetic function of cultural creative products, specific cultural elements are required as media. These cultural elements can be divided into two parts: the "life style culture" consisting of utensil civilization and behavior habits, and the "value culture" consisting of spiritual civilization and ideology. Therefore, the creative thinking of cultural creative products through the analysis of the audience's lifestyle, and on this basis to study the lifestyle and values that affect people, strive to make cultural creative products feedback people's spiritual life, stimulate people's interest in life, create an environment and use scenarios, to meet the psychological and spiritual needs of the audience. 


\section{Regional cultural characteristics}

Confucius's "harmony but difference" in "gentleman and difference" is a true description of the generalization of Chinese regional cultural characteristics. Since ancient times, China has created a splendid and precious culture for thousands of years because of its unique gerontological features and colorful human customs. Today's Chinese culture is the essence of many regional cultures since the development of Chinese history. They both retain commonness and certain individuality, and have certain conflicts and deep integration. At the same time, because China has advocated Confucianism since ancient times and retained the cultural characteristics of "harmony but difference" among regions, the main characteristics of Chinese regional culture can be summarized as regional, long-term, integration and diversity.As shown in figure 1.

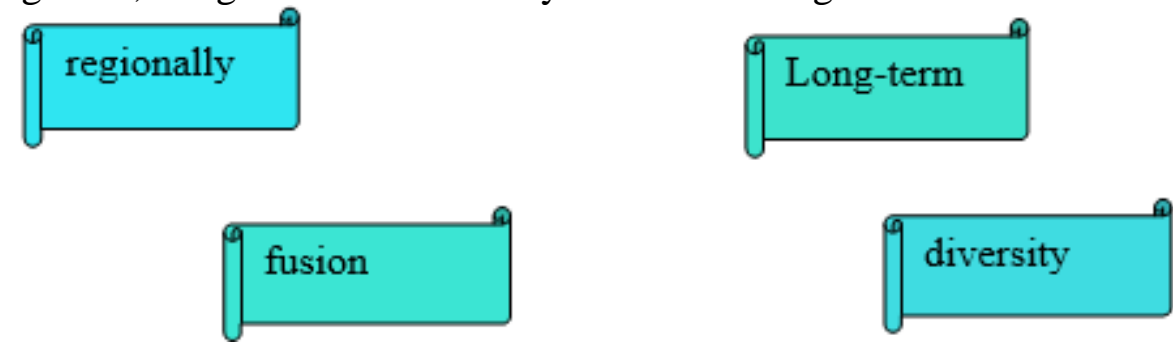

Figure 1. Regional Cultural Characteristics

\subsection{Regionally}

The so-called "one side of water and soil nurtures one side of the people, one side of the people nurtures one side of the culture" describes the regional characteristics of regional culture. The development of Chinese civilization has a long history and vast territory. Therefore, different cultural characteristics of China lie in the differences caused by different regions. For example, $\mathrm{Wu}$ culture is characterized by the "intelligent and artistic" culture with the characteristics of Yum Xiang, while Guangzhou Plateau culture is characterized by the "ethnic minority" culture with the characteristics of karat land forms.

\subsection{Long-term}

China has experienced thousands of years of changes and development, and its regional culture has formed distinct characteristics in the long-term precipitation. In the constant adaptation and innovation, human beings have achieved unique regional cultural characteristics in the long run. The long-term nature of China's regional culture is reflected in the process in which the regional environment promotes human progress, human beings further create civilization, and after civilization influences human beings, human beings further adapt to and improve the environment.

\subsection{Fusion}

Since ancient times, blockade has been the main cause of hindering cultural development and resulting in the lack of ideological exchanges. Although the development of Chinese culture fluctuates in the long history, it eventually forms a bright and brilliant culture, which is inseparable from the infiltration and integration of regional cultures. At the same time, it also includes absorbing the essence of foreign culture, so that Chinese culture has the characteristics of a variety of regional cultures. 


\subsection{Diversity}

China's regional culture is characterized by diversity in its development. On the one hand, it originates from the changes and unification of different regimes in history, which makes the national culture evolve continuously, but at the same time it can be partly preserved and inherited. On the other hand, the natural environment, customs, political culture and folk customs have jointly become the characteristics of China's regional culture. As an integral part, the natural and human factors of Chinese regional culture have been fully integrated and innovated.

\section{The Current Situation and Trend of the Development of Enchanting Products}

Literary products refer to innovative product design oriented by "culture + creativity". In recent years, in response to the country's vigorous development of creative products:

$\diamond \quad$ It stems from the state's emphasis on the innovation of traditional Chinese culture.

$\diamond$ It shows the cultural self-confidence of the country. Throughout the historical changes, whether in the flourishing period of the Tang Dynasty or Bhang Asian's Silk Road mission, the self-confidence of the national culture is highlighted. This shows that China attaches great importance to the development of literary and creative products.

$\diamond$ With the rapid improvement of the national economy and the strong support of the state for the cultural and creative industries, more and more regions have increased their investment in the cultural and creative industries, or in the form of the creation of cultural brands, or in the form of innovative forms of peripheral products such as museums and cultural relics bureaus, striving to enhance the experience of modern consumers through cultural and creative products, thus creating a soft power of culture. As shown in figure 2.

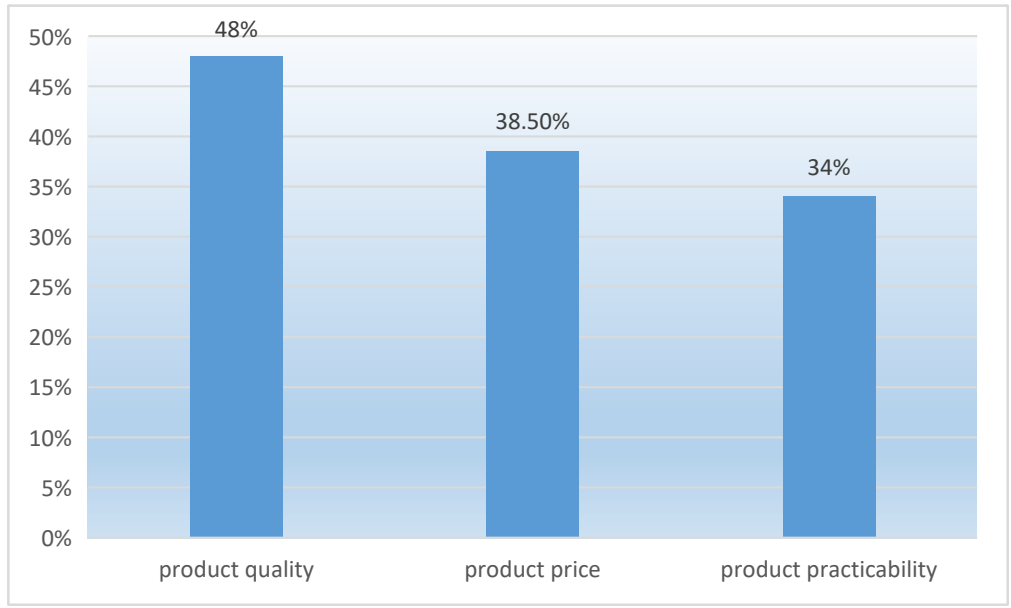

Figure 2.Requirements for Product Quality, Price and Practicality

Consumers also have high requirements for product quality, price and practicability, which are $48 \%, 38.5 \%$ and 34\% respectively. Product quality is very important for product sales, only high-quality products will be recognized by the public. And the price should be reasonable. In the survey of price factors, $43.5 \%$ of consumers can accept products of 100 yuan to 200 yuan, 30.5\% of consumers can accept products of less than 100 yuan, $19.5 \%$ of them are 200-500 yuan, and only $6.5 \%$ are more than 500 yuan. Moreover, the development of cultural and creative products should pay attention to practicality, not practical products, even if consumers buy back for a long time will be put on the shelf, gradually fading out of people's lives.

Moreover, although many creative products have been recognized by consumers in the existing market, most of them lack regional cultural characteristics, such as tourist souvenirs as a kind of 
creative products, there are fewer types of domestic tourist souvenirs with strong commercial flavor, and most of the tourist souvenirs sold in scenic spots are the same. It can be seen from this that creative products oriented by consumerists and regional cultural characteristics will inevitably upgrade traditional creative products and convey unique cultural characteristics. For example, the "Lilian Shantung Li"metal bookmark of the Palace Museum originated from the famous painting "Lilian Shantung Tu" of the Song Dynasty. As a realistic landscape painting, Lilian Shantung Picture depicts the scenes of mountains standing on the banks of rivers, lakes and marshes. Most of the modeling elements of mountains and Moors in the painting come from the peaks of Lush an Mountain in the area of Loyang Lake.

When it comes to Dushanbe's beautiful scenery, only its magnificent and dangerous complex landscapes are known. Among them, the magnificent scenery of double waterfalls and quadrant waterfalls is the most amazing. The Metal Bookmark Design of "Lilian Shantung Li" perfectly reproduces the regional landscape features of the Kaifeng, Jun ling, Weird Stone Cave and Deep Canyon of Lush an Mountain in front of modern people, and ingeniously creates a natural picture of the integration of the mountain peak and the mighty Yangtze River and the Bib Loyang Lake.In the material design, the brass gold-plated metal material is selected to be hard and bright lines after laser engraving, and the clip-type design processing is carried out. As if mountains and rivers stand on the books, the artistic form of traditional paintings in which painters place their feelings between mountains and rivers can be applied to the design of modern literary products, aiming at creating a spectacular landscape with thousands of miles of peaks and magnificent mountains and rivers in the area of Loyang Lake.

\section{Design Strategy of Literary Creation Products from the Perspective of Regional Culture}

\subsection{Culture Promotes Innovation}

The so-called culture promotes innovation, mainly through the symbolization of cultural language, the modernization of regional culture and the connotation of functional symbols, to realize how to promote the creative design form of creative products through culture. By symbolizing the abstract cultural language, some obscure and difficult traditional cultures can be symbolized, while ensuring the heritage and development of culture.

\subsection{Aesthetics Promotes Innovation}

With the rapid development of society, homogeneous and innovative creative products can no longer attract the attention of consumers. Therefore, we can promote the innovative forms of creative products through aesthetics, enrich the commercial market through diversification and modernization of product forms, and at the same time, inherit and carry forward the excellent regional culture of China.

\subsection{Demand Promotes Innovation}

Demand-driven innovation is an effective breakthrough in the design of creative products. By clarifying consumerism for the functions of creative products, we can understand the inner demands of modern consumers for creative products and the acceptance of the market for the development of creative product design, so as to realize the healthy development of cultural innovative products, product-rich markets and consumer culture in the market. 


\section{Conclusion}

The creative dimension of cultural creative product design can be developed from three aspects: the acquisition of lifestyle and creativity, the expression of values and creativity, and the influence of lovely cultural factors on creativity. Cultural and creative product design itself is a visual statement of "values" and "lifestyle" related to products by designers. Designers grasp the visual semantics of relevant values and lifestyles, and convert them into modelling language, so that audiences can obtain sufficient information, cognitive and emotional identity, and ultimately achieve the purchase behavior, so as to achieve the dissemination of regional culture.

\section{Acknowledgement}

Research on Visual Communication Professional Talents Training Model Based on Knowledge Transformation Model /2018 Fujian Youth and Youth Project (Social Science) JAS180733

\section{References}

[1] Bu Weigh, Lamming. The role of illustration art in the design of creative products and its application principles [J]. Human Packaging, 2018,33(02): 88-91.

[2] Gavin Rosemary, Paul Harris, Design Thinking [M]. China Youth Publishing House, 2010.

[3] Bu Henge. Design Semiotics [M]. Songhua University Press, 2008:95-103.

[4] Li Shana. Design is the economy - the individualized turn of Taiwan's creative cultural commodities [J]. Strait Science and Technology and Industry, 2012 (Z1): 84-89.

[5] Fang Tan Kenyan. On Lovely [M]. Shannon People's Publishing House, 2011:151-164. 